\title{
Preterm Preeclampsia and Timing of Delivery: A Systematic Literature Review
}

\author{
Tatiana Henriques Leite ${ }^{1}$ Vitor Barreto Paravidino ${ }^{1}$ \\ ${ }^{1}$ Institute of Social Medicine, Universidade do Estado do Rio de \\ Janeiro, Rio de Janeiro, RJ, Brazil \\ Rev Bras Ginecol Obstet 2018;40:499.
}

Address for correspondence Tatiana Henriques Leite, PhD, Universidade do Estado do Rio de Janeiro, Rua São Francisco Xavier, 524, 20550-900, Maracanã, Rio de Janeiro, RJ, Brazil (e-mail: henriques.tatiana@gmail.com).

In addition, Guide et al $(2017)^{4}$ pointed out several recommendations based on the results of this review. However, these recommendations were not classified according to the grading of recommendations assessment, development and evaluation (GRADE) system, taking into account the level of evidence and grading of recommendations. ${ }^{7}$

In summary, this review analyzed an important question; however, the authors should have performed an exhaustive search of the literature and used an appropriate methodological approach. Due to these limitations, any conclusion or recommendation concerning the results of this review should be interpreted with caution.

Conflicts of Interest

None to declare. Cochrane Handbook for Systematic Reviews, three databases should be considered when searching for trials: Medline, Embase and CENTRAL. ${ }^{5}$ In Brazil, the Ministry of Health recommends that a systematic review should include at least five databases; four essential databases (Medline, Embase, CENTRAL and Lilacs) and one area-specific database. ${ }^{6}$ This is an important issue because this procedure ensures that all evidence can be found. Secondly, the search strategy was limited to a 3-year period. This approach ignores all evidence produced before and is not recommended, especially in an update paper. ${ }^{5}$ Lastly, the authors reported that the search in the Medline was performed using Medical Subject Headings (MeSh) (preeclampsia, parturition and timing of delivery). However, these search terms are not sufficient, and MeSh such as "Labor, Obstetric," "Delivery, Obstetric" and "labor, Induced" should also be included. All these limitations combined would result in missing articles, influencing the results of this review.

Another important limitation is the lack of risk of bias assessments (qualitative assessment). This tool evaluates the risk of overestimating or underestimating the true effect of the intervention. This is the only available strategy to evaluate internal validity-an important criterion in epidemiologic studies. Therefore, according to the Cochrane Handbook for Systematic Reviews, a qualitative assessment is part of the systematic review method. ${ }^{5}$

\section{References}

1 Say L, Chou D, Gemmill A, et al. Global causes of maternal death: a WHO systematic analysis. Lancet Glob Health 2014;2(06):e323-e333 Doi:10.1016/S2214-109X(14)70227-X

2 Chappell LC, Milne F, Shennan A. Is early induction or expectant management more beneficial in women with late preterm preeclampsia? BMJ 2015;350:h191 Doi:10.1136/bmj.h191

3 Koopmans CM, Bijlenga D, Groen $\mathrm{H}$, et al; HYPITAT study group. Induction of labour versus expectant monitoring for gestational hypertension or mild pre-eclampsia after 36 weeks' gestation (HYPITAT): a multicentre, open-label randomised controlled trial. Lancet 2009;374(9694):979-988 Doi:10.1016/S0140-6736(09)60736-4

4 Guida JPS, Surita FG, Parpinelli MA, Costa ML. Preterm preeclampsia and timing of delivery: a systematic literature review. Rev Bras Ginecol Obstet 2017;39(11):622-631 Doi:10.1055/s-0037-1604103

5 Higgins JPT, Green S, Eds. Cochrane Handbook for Systematic Reviews of Interventions Version 5.1.0. London: The Cochrane Collaboration; 2011 http://handbook-5-1.cochrane.org/. Accessed December 8, 2017.

6 Ministério da Saúde. Secretaria de Ciência, Tecnologia e Insumos Estratégicos. Departamento de Ciência e Tecnologia. Diretrizes Metodológicas: Elaboração de Revisão Sistemática e Metanálise de Ensaios Clínicos Randomizados. Brasília, DF: Ministério da Saúde; 2012

7 Ministério da Saúde. Secretaria de Ciência, Tecnologia e Insumos Estratégicos. Departamento de Ciência e Tecnologia. Diretrizes Metodológicas: Sistema GRADE - Manual de Graduação da Qualidade da Evidência e Força de Recomendação para Tomada de Decisão em Saúde. Brasília, DF: Ministério da Saúde; 2014
DOI https://doi.org/ 10.1055/s-0038-1668529. ISSN 0100-7203.
Copyright (๐) 2018 by Thieme Revinter Publicações Ltda, Rio de Janeiro, Brazil

\section{License terms}

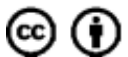

